FUNDAMENTOS, TEORIAS E ASPECTOS METODOLÓGICOS DISCIPLINARES APLICADOS NA BIÔNICA E BIOMIMÉTICA 


\section{SOBRE A AUTORA}

Ana Veronica Pazmino I ana.veronica@ufsc.br Lattes: http:/lattes.cnpq.br/9694149439296427

Graduação em Desenho Industrial pela Universidade Federal do Rio de Janeiro. Mestre em Engenharia de Produção e Sistemas pela Universidade Federal de Santa Catarina. Doutora em Design pela PUC-Rio. Professora do curso de Design da Universidade Federal de Santa Catarina - UFSC. Áreas de pesquisa: Metodologia de Projeto, Projeto de Produto, Ensino de Design, Design e Meio Ambiente. Professora Doutora, Dep. de Expressão Gráfica, Curso de Design de Produto, UFSC, Florianópolis. 


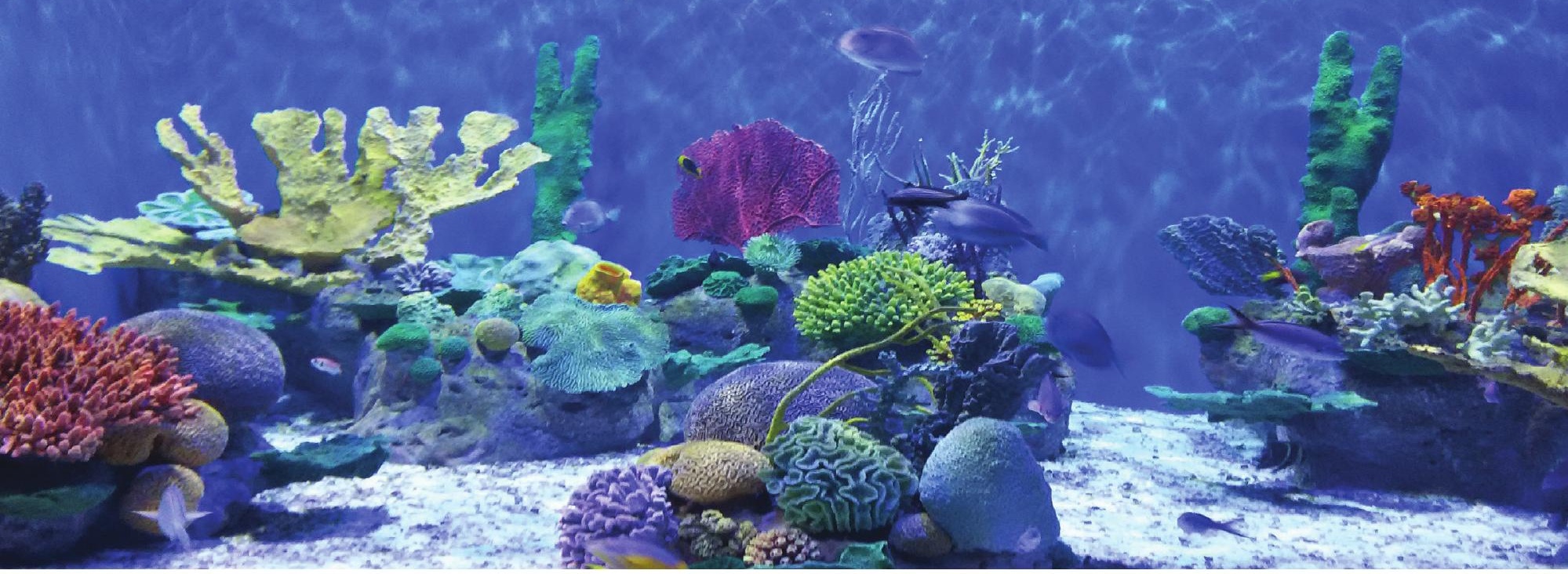

\title{
Interdisciplinaridade como Meio para o Fortalecimento da Biônica e Biomimética nos Cursos de Design
}

\author{
Interdisciplinarity as a Means to Strengthen Bionics \\ and Biomimetics in Design Courses
}

Ana Veronica Pazmino

\section{Resumo}

Este artigo apresenta uma reflexão sobre a necessidade da prática interdisciplinar com conhecimentos relacionados a biologia, ecologia e biotecnologia no campo do design. 0 artigo enfatiza que a biônica e biomimética devem ser incentivadas como abordagens importantes em prol da inovação e sustentabilidade. A pesquisa documental mostra a diferença de Biônica e Biomimética e sua importância relacionada a um maior conhecimento da natureza que podem servir de auxílio ao desenvolvimento de produtos mais inovadores e adequados ao meio ambiente. Como resultado, o artigo defende a necessidade de pesquisas sólidas de sistemas naturais e de uma relação interdisciplinar com saberes relacionados a biologia como forma de encontrar soluções para o projeto de produtos sustentáveis.

Palavras-chave: Interdisciplinaridade; Biônica; Biomimética; Ensino de design.

\section{Abstract}

This paper presents a reflection on the need of interdisciplinary practice with knowledge related to biology, ecology and biotechnology in the field of design. The article emphasizes that bionics and biomimetics should be encouraged as important approaches to innovation and sustainability. The documentary research shows the difference of Bionics and Biomimetics and their importance related to a greater knowledge of nature that can serve as aid to the development of products more innovative and appropriate to the environment. As a result, the article advocates the need for solid research on natural systems and an interdisciplinary relationship with biology-related knowledge as a way to find solutions for sustainable product design.

Keywords: Interdisciplinary; Bionics; Biomimetics; Teaching design. 
Complexo pode ser entendido como um tecido de acontecimentos, ações, interações, determinações, acasos que constitui o processo.

O modo de pensamento ou de conhecimento fragmentado, monodisciplinar e simplesmente quantificador, tomando como critério de construção o ponto de vista (o paradigma) de um ramo do saber autodeterminado ou disciplina, com todos os seus interesses subjacentes, $e ́$ responsável pela prevalência de uma inteligência bastante miope ou cega na medida em que é sacrificada a aptidão humana normal de religar os conhecimentos em proveito da capacidade de separar ou desconectar. (JAPIASSU, 2006, p. 15)

\section{INTRODUÇÃO}

O conhecimento do designer de produtos organiza-se a partir de conhecimentos para criar soluções que se materializam em artefatos. 0 conhecimento está profundamente atrelado à cultura e à sociedade, lembrando que estas transformam-se, evoluem, progridem e regridem. Para Tronca $(2006$, p. 65) o saber hoje tem que ser repensado considerando-se a grande massa de informação e saberes.

Sabe-se que o processo de design é complexo, pode parecer que complexidade supõe confusão, desordem, incerteza, mas ordem e desordem são processos constitutivos da complexidade e, portanto do processo de design; dessa forma, o pensamento do designer deve ser abrangente, multidimensional, capaz de compreender a complexidade envolvida e construir novos conhecimentos que levem em considerações novas problemáticas.

As relações das fases projetuais que constituem o processo de design devem ser presididas por integrações de métodos, conhecimentos e teorias de diversas disciplinas. Assim, o processo de design não é apenas constituído pelas fases projetuais, mas pelas ações que se estabelecem entre elas. 0 conjunto dessas relações constitui a organização do processo projetual.

Se considerarmos que dentro do processo de projeto há uma sequência de passos que partem de uma necessidade ou um problema até a solução ou produto, entende-se que deveria existir em cada passo um conjunto de ações que deveriam ser realizadas por uma equipe interdisciplinar formada por indivíduos com pontos de vista cognitivamente diversos permitindo uma inter-relação de múltiplas ideias, informações, opiniões, teorias em intercambio contínuo.

A complexidade da dimensão da sustentabilidade exige uma postura diferente do designer, este artigo propõe que o design seja um campo que abrace um corpo de conhecimentos diversos para se tornar um campo de design orgânico que integre de forma reflexiva e responsável disciplinas que permitam um desenvolvimento sustentável. Parafraseando Japiassu (2066) é necessário que as instituições de ensino criem lugares permanentes de trocas e debates permitindo aos diversos "especialistas" colocar em comum suas experiências.

Para Tronca (2006, p. 76) "considerando o mundo em constante transitoriedade, onde o conhecimento evolui de forma incontrolável e a quantidade de novas informações disponíveis é cada vez maior, é impossível que maneiras reducionistas de aprendizagem persistam".

\section{A INTERDISCIPLINARIDADE}

A interdisciplinaridade surgiu como uma nova atitude frente ao saber. Ela reconhece as disciplinas, mas promove, num exercício coletivo de saberes (integração possibilitada pela continua intercomunicação). Na concepção de Demo (1997, p. 114) (...) a interdisciplinaridade representa a orquestração intrínseca das disciplinas, fazendo convergir seus pontos diversificados de origem. Para Fazenda (1991, p. 31) (...) seu princípio é sempre o mesmo: 
caracteriza-se pela intensidade das parcerias entre especialistas e pela integração das disciplinas.

Segundo Fazenda (1979, p. 8) "a interdisciplinaridade antes que um "slogan" é uma relação de reciprocidade, de mutualidade, que pressupõe uma atitude diferente a ser assumida frente ao problema do conhecimento, ou seja, é a substituição de uma concepção fragmentária para unitária do ser humano". Para a autora, uma condição de efetivação da interdisciplinaridade é o desenvolvimento da sensibilidade sendo necessário um treino na arte de entender e esperar, um desenvolvimento da criação e da imaginação. (Figura 1)

- A necessidade da interdisciplinaridade no campo do design é a exigência pela complexidade da sustentabilidade. Ela pode auxiliar na compreensão do problema ambiental e na reforma do pensamento e do ensino de
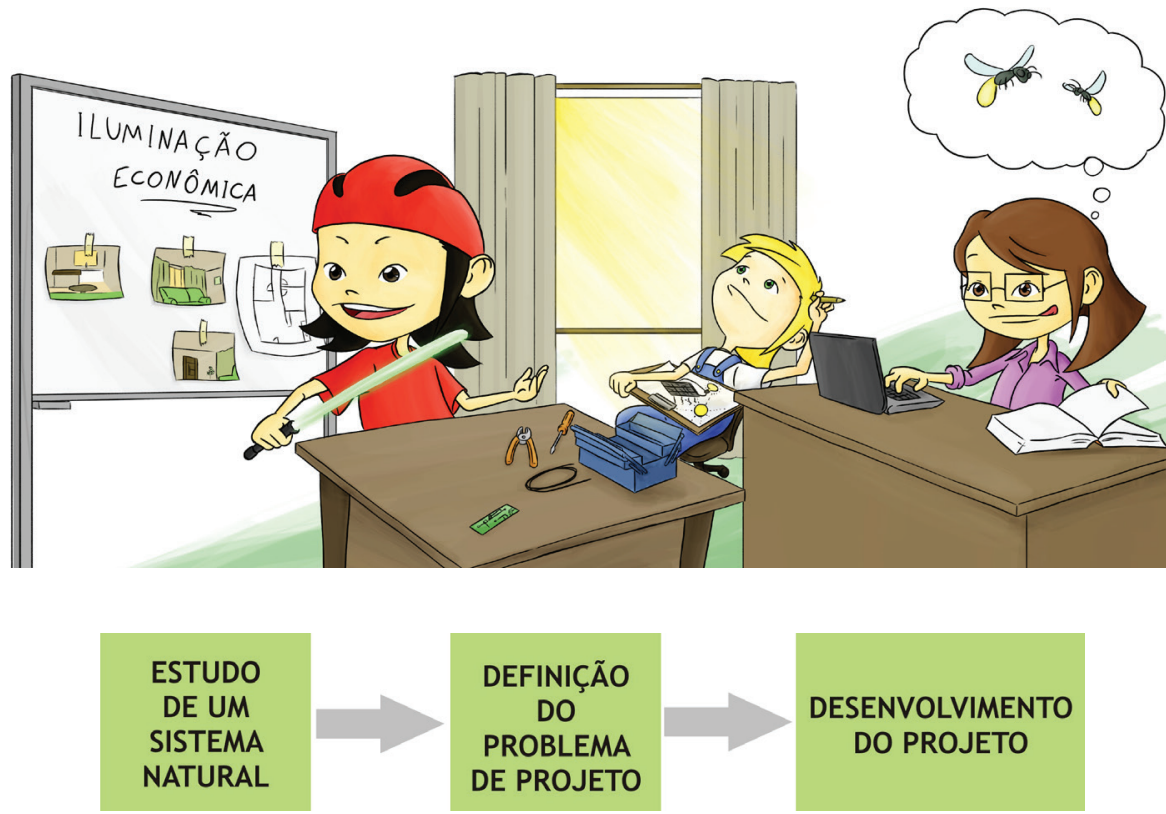

design, para integrar disciplinas correspondentes aos problemas atuais e futuros. Não é possível nos contentar com a justaposição de disciplinas diante da complexidade da problemática ambiental e social. É necessário pensar amplamente, vencer a miopia dos saberes fragmentados e do ponto cego dos impactos ambientais e sociais dos projetos, consumos e comportamentos.

Conhecimentos da biologia, ecologia, química, sociologia, psicologia entre outros deveriam implicar transferências de saberes, originando um novo corpo disciplinar com o design, criando um novo e maior padrão epistemológico. Isto se configura como uma utopia, imaginar que o campo do design possa ser melhor ao materializar objetos ambientalmente corretos e contribuir com valores éticos no comportamento da sociedade.
Figura 1: Equipe de projeto indisciplinar Fonte: Pazmino 2017. 
Espaço social onde se realizam as trocas de bens.
A distância entre a utopia e a realidade vem por depoimentos de autores que mostram a dificuldade de praticar a interdisciplinaridade. Couto (1997) diz que no campo do ensino de Design, a prática tem mostrado que propostas efetivas de trabalho interdisciplinar raramente se têm consolidado no ambiente universitário. Também Bomfim (1997) apontava que quando um designer procura, por exemplo, utilizar elementos da ergonomia, da estética e da semiótica na configuração de um objeto, depara-se, com situações antagônicas, pois estas ciências emitem enunciados em códigos diferentes, não havendo estágio intermediário, algo como uma "ergoesteticoótica". Este fato anedótico nos faz refletir que se não existe interdisciplinaridade entre o design e disciplinas consolidadas na grade do curso como ergonomia, estética e semiótica. Qual seria o caminho para uma interdisciplinaridade com disciplinas que não fazem parte de um curso de design, como biologia ou química?

Follari (1995, apud, Couto, 1997) menciona que fora da universidade, onde o objetivo não é gerar conhecimentos, mas resolver problemas práticos, a vigência do interdisciplinar, de modo geral, é mais imediata e praticada com sucesso. Nestes casos, não existem muitos preconceitos epistemológicos e ninguém se inquieta em juntar-se aos diversos profissionais com um objetivo eminentemente prático.

Dessa forma, se o design é uma atividade, que utiliza, na sua prática, conhecimentos de outros campos do saber, o caminho da interdisciplinaridade pode ser dirigir o ensino para a solução de problemas ambientais práticos, facilitando o diálogo e parceria de diversos pesquisadores, profissionais, professores e alunos. Aproximando a academia ao "mercado". Abrindo pontes com indústrias e usuários por meio de projetos de extensão ou pesquisa e com cursos de pôs graduação. Este último tem mostrado resultados consistentes na configuração de trabalho conjunto.

Além de aproximação ao real, a abertura ao diálogo é colocada por vários autores como uma imprescindivel prática educativa. Para Japiassu (2006) "é preciso que todos estejam abertos ao diálogo, que sejam capazes de reconhecer aquilo que lhes falta e que podem ou devem receber dos outros. (...) Para que todos estejam abertos ao diálogo é necessário haver uma tomada de consciência, primeiramente individual."

Segundo Japiassu (2006) a interdisciplinaridade ajuda a mudar e se aperfeiçoar. Pois cultiva o desejo de enriquecimento por enfoque novo, o gosto pela combinação das perspectivas e alimenta a vontade de ultrapassagem dos caminhos já batidos e dos saberes já adquiridos.

Cabe então, ao educador primeiramente desenvolver o diálogo reflexivo, sólido e crítico que respeita as ideias e saberes dos outros e que transforma seus conceitos e saberes. Além disso, cabe incentivar a curiosidade dos educandos de forma contínua, problematizar a situação ambiental, mostrar a necessidade de conhecimento de outras áreas, com o objetivo de despertar a busca e o desenvolvimento de novos saberes fora e dentro do curso. 


\section{NOVOS SABERES PARA O DESIGN}

McDonough e Braungart (2010) mencionam, que se queremos prosperar devemos aprender a imitar a natureza em seu ótimo sistema eficiente do berço ao berço em relação aos fluxos de nutrientes e ao metabolismo, nos quais o conceito de resíduo não existe. Para os autores em um o metabolismo biológico um nutriente é um material ou produto projetado para voltar aos ciclos naturais para serem consumidos pelos micro-organismos do solo ou por outros animais. Significa também abandonar o conceito do berço ao túmulo que pressupõe um depósito para os resíduos.

Outro conceito que deveria ser substituído seria a eco eficiência por eco efetividade, para McDonough e Braungart (2010, p. 71) "Se a natureza teria aderido ao modelo humano da eficiência, haveria menos flores em uma cerejeira e menor quantidade de nutrientes. Haveria menos árvores, menos oxigênio e menos água pura. Haveria menos pássaros e menos diversidade".

Pelo dito acima, se percebe que uma disciplina que deveria ser integrada ao design é a biologia. Para Blüchel (2009, p. 38) "está atrasada uma pesquisa sistemática pelo homem sobre a competência de sistemas biológicos. Com isso, poderiam ser criados milhares de novos produtos, sobretudo benéficos à natureza, e inúmeros problemas da sociedade, economia e indústria poderiam ser conduzidos para soluções orientadas à natureza".

0 termo Biônica vem de BIOS que significa vida e NICA que é a parte final da palavra eletrônica, segundo (Broeck, 1989 apud Ramos, 1993), biônica é o estudo dos sistemas e organizações naturais visando analisar e recuperar soluções funcionais, estruturais e formais para aplicá-las na resolução de problemas humanos por meio da geração de tecnologias e concepção de objetos e sistemas de objetos.

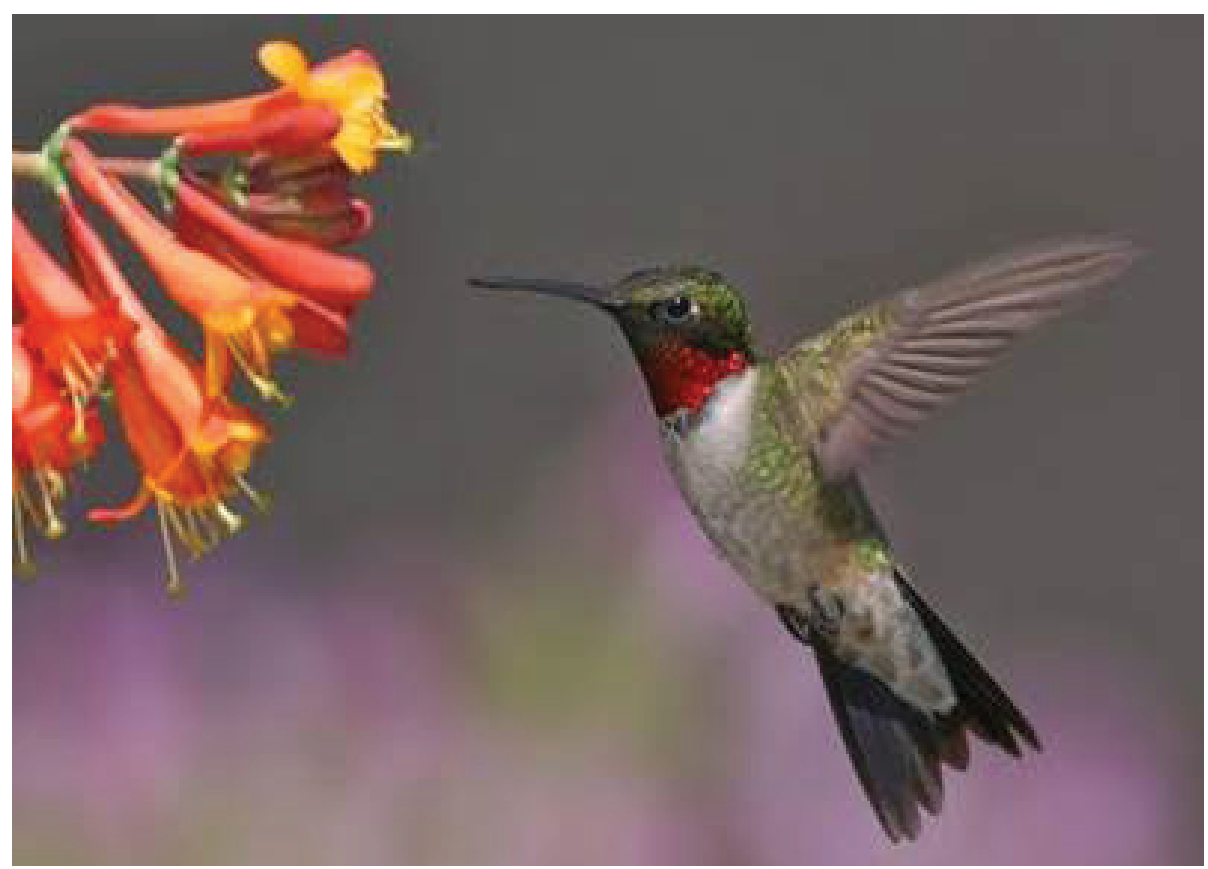

Por que a harmonia, que aparece tão claramente na natureza, não tem um papel essencial na nossa vida social? Nós estamos tão fascinados com nossa onipotência, com o poder de inventar e realizar, que talvez tenhamos perdido de vista a força dos limites. Mas, agora nós nos vemos de repente, obrigados a limitar a exploração de nossas riquezas materiais e o aumento da população (...) precisamos aprender novamente a economizar e nos moderar, encontrando as proporções certas e eficazes. (BLÜCHEL, 2009, p. 51)

Figura 2: 0 beija-flor-depescoço-vermelho (Archilochus colubris) voa mais de 800 quilômetros, do litoral sul da América do Norte ao México. Os beija-flores percorrem tantos quilômetros com o equivalente de 3 mililitros de combustivel. 


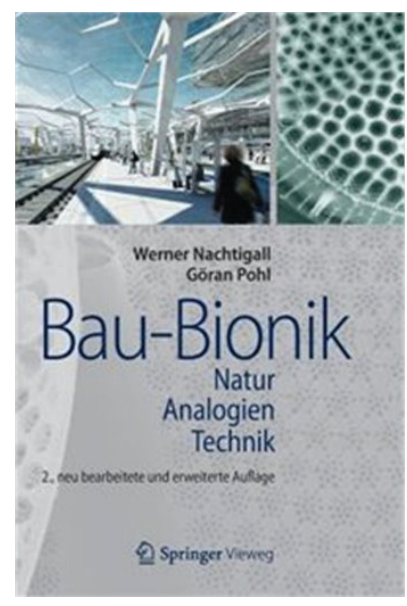

Figura 3: Livro de biônica.
O ser humano ao longo da história tem usado a natureza como fonte inspiradora de soluções para seus problemas, mas, conforme (BLUCHEL, 2009) a formalização da aliança da biologia e técnica, foi criada em 1958 pelo engenheiro da NASA, da Força Aérea dos EUA, major J.O. Steele, que desenvolveu como ciência ampla. Deve-se considerar que em 1958 não havia nenhuma preocupação ambiental, estava vigente o Paradigma Social Dominante PSD que teria surgido durante o Renascimento e tem influenciado o modelo científico e social desde esse tempo, com uma visão antropocêntrica e antiecologista.

Para Bluchel (2009), o ciberneticista russo L. P. Kraismer, definiu a biônica como "A ciência que examina os processos e métodos biológicos, como o objetivo de aplicar os resultados obtidos no aperfeiçoamento de máquinas e sistemas velhos e na criação de novos". Já o engenheiro francês Lucien Gérardien definiu como "A arte de resolver problemas técnicos por meio do conhecimento de sistemas naturais". Hoje, o maior estudioso do assunto é o zoólogo Werner Nachtigall, é um dos pioneiros e precursor da biônica, nos anos noventa criou a disciplina de "Biologia técnica e biônica" e criou uma sociedade com o mesmo nome. (Figura 3)

Para (Nachtigall apud Bluchel, 2009), "A biônica significa que tudo é transferivel tecnicamente, também as tecnologias mais complexas da natureza, todas elas sem infringir as leis da natureza. A biônica não quer prescrever nada ao engenheiro, mas pô-lo diante do "espelho da natureza" e, com isso, exigir o máximo dele.

A biônica consiste em analisar sistemas naturais, seus princípios e suas características funcionais, com o objetivo de identificar princípios de solução, que devidamente adaptados possam vir a contribuir para solucionar problemas de projeto. Essas adaptações permitem criar formas análogas ou funções análogas.

As formas inspiradas na natureza são mais adequadas para modelar objetos, já que fazem parte da memória e cultura do ser humano. 0 estudo dos sistemas naturais possibilita a redescoberta de formas que sempre existiram e a utilização e adaptação dessas formas para configurar ambientes, produtos com mais equilíbrio e harmonia.

A Biônica como técnica criativa tem sido superficialmente pesquisada e aplicada no design. A bibliografia e produção com o uso da técnica têm sido em função de inovar e otimizar formas e funções de produtos com base nos sistemas naturais. Porém, a abordagem ecológica não foi incorporada à biônica. Surge aqui um campo de pesquisa integrando a biologia sob um olhar de complexidade, inteligência ecológica e consciência da inter-relação da natureza.

Segundo (Gomes, 1985) como em outras técnicas que utilizam a analogia, a biônica não é uma simples comparação e aplicação de resultados encontrados no mundo natural, mas uma análise de "princípios de funcionamento e solução" de processos biológicos.

A solução de problemas por meio da biônica não é uma atividade nova. A natureza frequentemente serviu de fonte de soluções as atividades do homem. O ser humano primitivo já a utilizava para resolver seus problemas diários. Ao deixar as cavernas nossos ancestrais se inspiraram em abrigos e ninhos dos pássaros para construir as primeiras casas com barro e pedaços de madeira. 
Algumas invenções primitivas surgiram da analogia com elementos naturais como: pentes e os esqueletos dos peixes; martelo com o punho fechado e o antebraço, a ponta do arpão semelhante ao ferrão dos insetos e aos espinhos de algumas plantas.

A utilização de princípios biológicos no projeto de máquinas pode ser vista nos trabalhos de Leonardo Da Vinci que estudou o voo dos pássaros, analisando o batimento das asas. Com esse conhecimento projetou inicialmente asas movidas pelo batimento comandado pelos braços.

Coineau e Kresling (1986) mencionam que Clément Ader em 1890 seguindo o modelo do morcego construiu o ĹEole. Este aparelho teria realizado a primeira decolagem de uma máquina mais pesada que o ar, movida a motor. (Figuras 4)

Segundo (Bonsiepe, 1978) para estimular a capacidade de captar os detalhes tridimensionais e os princípios formais que os estruturam, é viável a análise biônica dos fenômenos formais da natureza. Essa análise serve para aumentar a capacidade de transformação, isto acontece quando se analisa profundamente um objeto análogo.

A morfologia estrutural tem sido aplicada por muito tempo nas faculdades de engenharia e arquitetura. Toma-se como ponto de partida, um fenômeno natural a partir do qual se desenvolve uma solução de projeto. Esta prática tem sido feita de forma superficial sem aprofundamento na pesquisa da biologia e da técnica. (BLUCHEL, 2009) lembra que para os interessados na biônica é necessária uma cooperação interdisciplinar, um trabalho em conjunto com biólogos treinados técnica e analiticamente.

A aplicação da biônica no design de produtos vem sendo feita por meio de uma pesquisa básica: identificando sistemas naturais com características úteis para serem aplicadas em novos produtos ou em produtos já existentes. E na pesquisa aplicada que parte de problemas de projeto e busca nos sistemas naturais soluções que possam contribuir para resolvê-los.

\section{A UTILIZAÇÃO DA BIÔNICA NO DESIGN DE PRODUTOS}

Ramos (1993) apresenta procedimentos para a utilização da Biônica no design de produto que são:

- Quando não se tem um problema de projeto. A partir de uma pesquisa e análise de um sistema natural, são extraídas as informações promissoras e inovadoras relativas à função, formas, material e contexto que possam ser aplicados na resolução de necessidades por meio do desenvolvimento de um produto análogo. Neste procedimento é importante coletar muita informação, manter a mente aberta para que possam surgir insights para definição de um problema de projeto e posteriormente desenvolver soluções de produtos ou serviços aplicando as características do sistema natural. A dificuldade está em que este procedimento deve ser realizado quando não se tem presa no desenvolvimento de um produto, já que a pesquisa deve ser aprofundada para ter dados importantes para um projeto no futuro. A Figura 5 e 6 mostra o esquema deste procedimento.

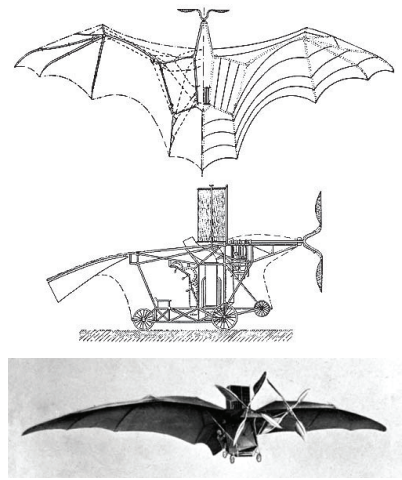

Figuras 4: Ader Eole. 
Figuras 5 e 6: Carrapicho e Vista microscópica do carrapicho.
Um exemplo deste procedimento foi aplicado no desenvolvimento do velcro. Segundo (CHALLONER, 2010 p. 733) o engenheiro suíço George de Mestral teve a ideia para o velcro em 1941, depois de pegar seu microscópio para estudar rebarbas presas ao pelo de seu cão e a sua roupa durante um passeio pelos Alpes. Estas rebarbas eram sementes bardana que tem vários ganchos que se prendem com facilidade aos pelos ou roupas. Mestral percebeu o potencial de um prendedor que usasse ganchos fortes de um lado e um tecido laceado ao qual os ganchos se prendessem do outro, e o chamou de Velcro, das silabas das palavras francesas velour (veludo) e crochet (gancho). (Figuras 5 e 6)
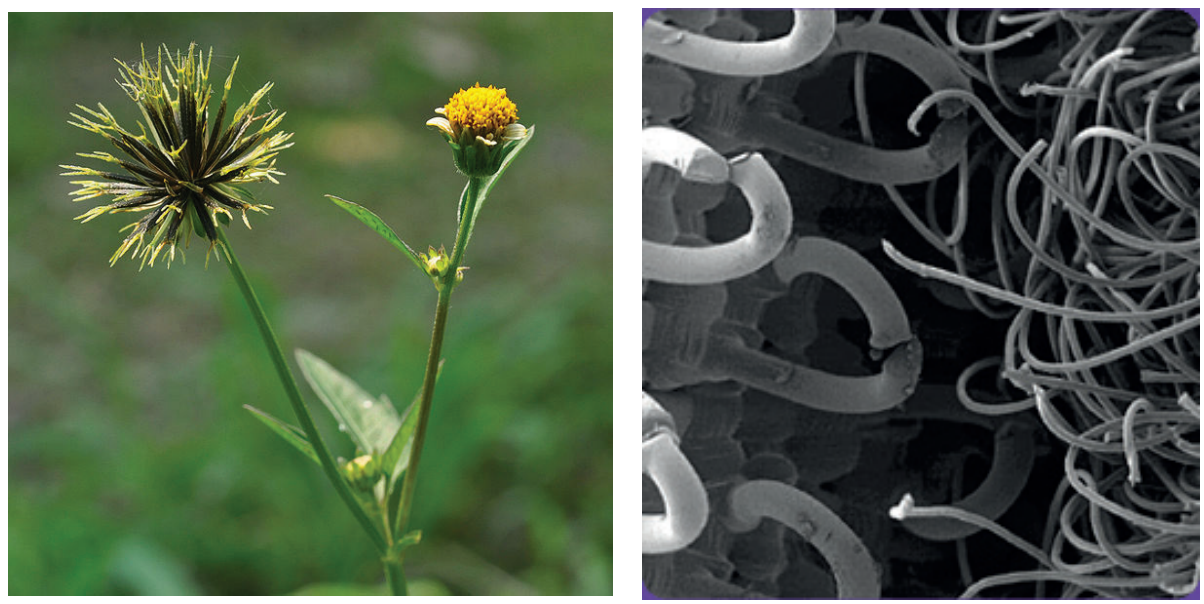

- Esse procedimento, parte de problemas existentes em um projeto, passando a pesquisa de um sistema natural. Procura-se na natureza, a solução para problemas semelhantes e de como aplicar tal conhecimento no projeto. Neste procedimento parte-se de um problema de projeto já definido. A dificuldade deste procedimento está em encontrar os sistemas naturais adequados as soluções específicas, pois, a busca em diversos sistemas naturais demanda tempo e uma ação interdisciplinar. A Figura 7 mostra o esquema.

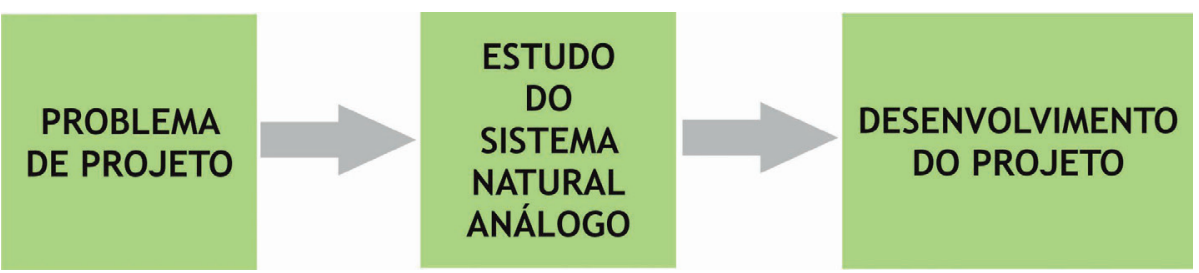

Um exemplo deste procedimento foi do projeto do helicóptero Dragonfly HC3 da empresa Sikorsky que tinha como problema de projeto o transporte de militares e artilharia. 0 sistema natural analisado foi o voo das libélulas. 0 corpo da libélula é semelhante a uma estrutura helicoidal, duas asas estão dispostas em forma cruzada sobre o corpo. Esta estrutura permite uma manobra extraordinária. Pode parar e voar de imediato na direção oposta. Alternativamente, pode 
permanecer suspendida em um ponto no ar e desde essa posição mover-se rapidamente. (Figuras 8 e 9 )

A IBM, que assistiu a Sikorsky neste projeto, introduziu um modelo de libélula no computador. Fizeram duas mil representações a partir de suas manobras de voo, para desenvolver o sistema análogo do protótipo.

- Este procedimento parte de uma necessidade ou função específica que o produto deve oferecer. Se inicia a pesquisa de um sistema natural que tenha uma função análoga. 0 problema deste procedimento é que a analogia foca num aspecto específico do sistema natural e não no sistema como um todo. Esquema na Figura 10.

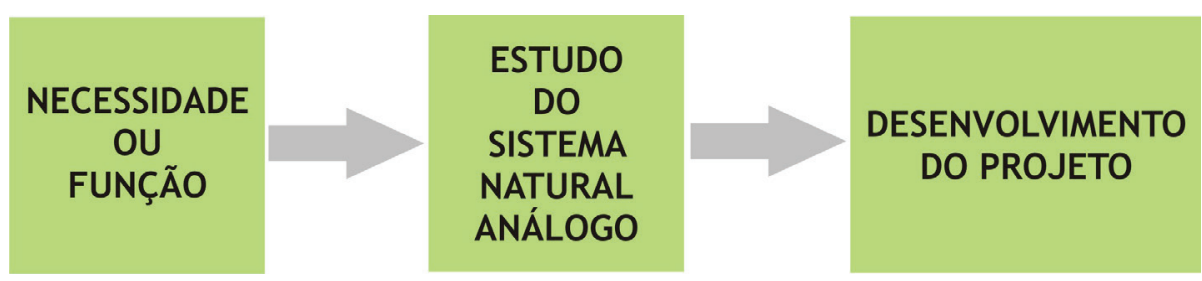

Um exemplo deste procedimento foi o desenvolvimento do tecido Fastskin da Speedo que precisava de um tecido para traje de banho para diminuir a fricção da água no corpo do atleta. 0 tecido tem a mesma aspereza da pele de um tubarão que imita os sulcos dérmicos, um tipo de escama capaz de oferecer eficiência hidrodinâmica no deslocamento e aumentar a velocidade do tubarão. (Figura 11)

Outro exemplo deste procedimento foi do Centro de Pesquisa EADS perto de Munique que buscavam uma solução para silenciar as hélices do rotor de um helicóptero. A pesquisa foi feita nas corujas cuja estrutura das asas permite que seu voo seja inaudivel para a maioria dos ouvidos. A solução foi deformar as hélices no canto posterior por meio de articulações de modo que os redemoinhos possam escapar de maneira flexivel e o barulho quase desaparece. Nos testes de túnel de vento, as fintas reduziram o ruído em 10 decibéis, um corte de $50 \%$ no ruído e não houve efeito sobre o desempenho da turbina. (Figura 12)

Nos três procedimentos, observa-se que a aplicação da técnica depende da pesquisa profunda do sistema natural para poder aplicar as características do sistema natural nos produtos. A pesquisa biônica precisa de uma abertura do designer para outras disciplinas tais como: biologia, física, mecânica, ecologia entre outras. Ou seja, a relação inter e multidisciplinar deve ser fortalecida para que os dados levantados na pesquisa biônica sejam aplicados com sucesso no projeto de produto.

Se a biônica se apresenta como uma técnica criativa que usa a analogia como meio para o desenvolvimento de produtos análogos. A Biomimética que vem das palavras BIOS, "vida", e MIMESIS, "imitação" surge como uma ciência mais completa, que não vê a natureza apenas como fonte criativa, mas, como medida: a Biomimética usa um padrão ecológico para ajuizar a "correção" de nossas inovações. Após 3.8 bilhões de anos de evolução a natureza aprendeu: o que funciona, o que é apropriado e o que dura.

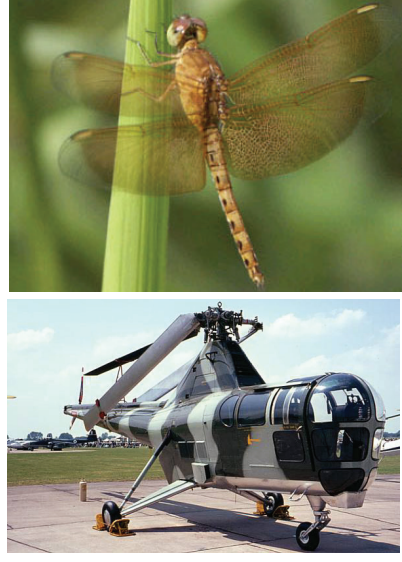

Figuras 8 e 9: Libélula e Dragonfly.

Figura 10: Terceiro procedimento. Fonte: Adaptado de Ramos, 1993, p. 39.

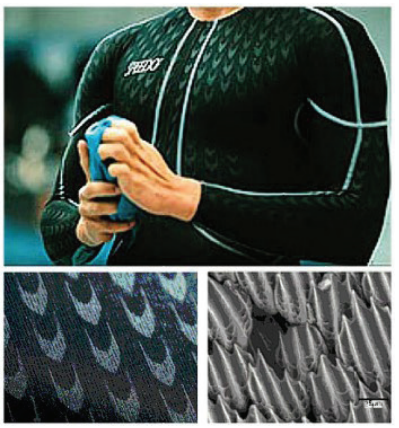

Figura 11: Fastskin Speedo.

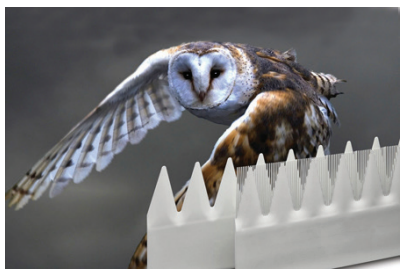

12: Coruja e material similar a estrutura das asas. 
A natureza leva seus limites a sério, produzir alimentos de acordo com a capacidade produtiva da terra, manter um equilíbrio energético.

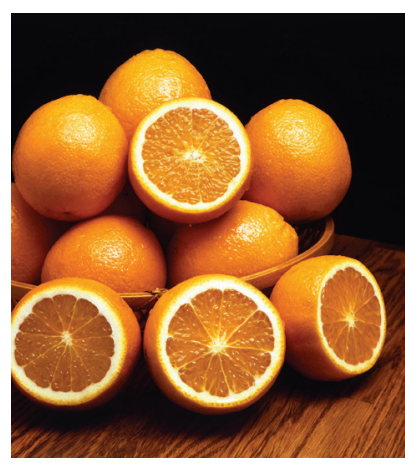

Figura 13: Laranja.

A natureza é movida a energia solar; usa apenas a energia de que precisa; adapta a forma à função; recicla tudo; recompensa a cooperação; confia na diversidade; exige especialização geograficamente localizada; inibe excessos; "explora o poder dos próprios limites" (BENYUS, 1997)

A natureza como mentora: a Biomimética é uma nova forma de ver e valorizar a natureza. Se baseia não no que podemos extrair da natureza, mas no que podemos aprender com ela. As soluções encontradas na natureza são eficazes. A estrutura natural do reino animal, vegetal ou mineral é regulada na sua evolução por precisas leis da física para se adequar ao meio ambiente. A Biomimética surge na década de 90 no meio de uma série de informações em relação as problemáticas ambientais, por este motivo traz no seu conceito uma abordagem mais ética e reflexiva.

A natureza sempre utiliza a menor quantidade de matéria e energia para obter o máximo desempenho. 0 entendimento de como a natureza faz isto, fornece base para o desenvolvimento de produtos que aproveitem melhor as características dos materiais, processos e descarte.

As frutas como a laranja, tangerina são produtos e embalagens que apresentam "absoluta coerência entre forma, função, consumo e descarte". Cada receptáculo é embrulhado individualmente por meio de películas, todas elas protegidas por uma casca forte e biodegradável. (Figura 13)

O floco de neve pode apresentar uma configuração variável determinada por forças como a temperatura, umidade, velocidade do vento formando uma grande variedade de configurações com a mesma matéria-prima. (Figura 14)
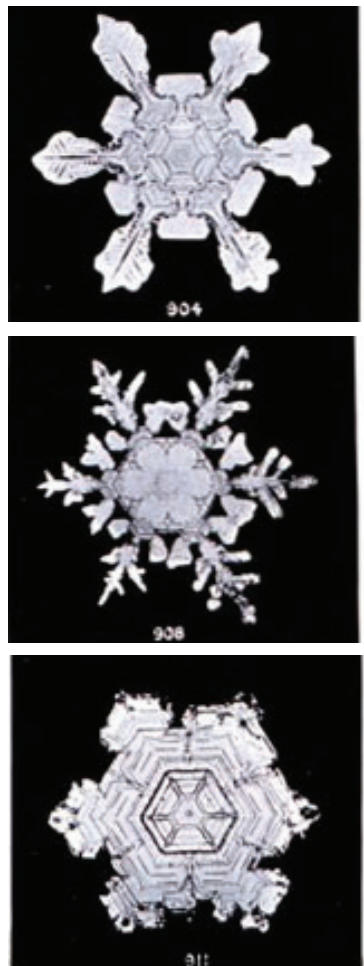
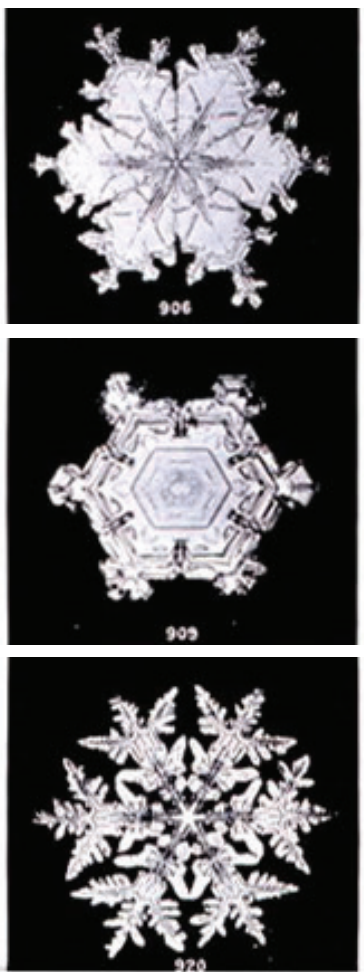
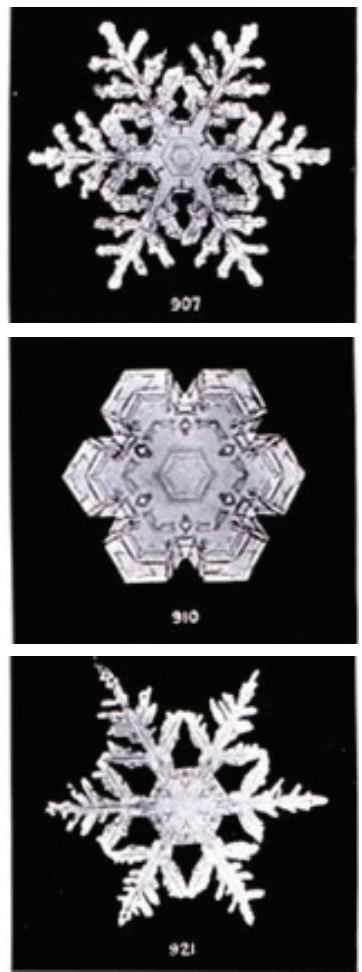

Figura 14: Floco de neve. 
Na natureza o reaproveitamento dos materiais torna-se simples, a técnica orgânica constitui de um ou dois materiais. Um para dar estrutura (por exemplo, osso) e outro universal de forma e função (p. ex. tecido). Facilitando a biodegradação.

0 trânsito pode-se inspirar em como multidões de insetos, peixes e pássaros mostram com perfeição invejável sua regulagem automática de distância para evitar colisões. Por tanto, existe um motivo evidente para se procurar entender as formas e estruturas empregadas na natureza.

Abelhas, tartarugas, e pássaros locomovem-se sem mapas, ao passo que baleias e pinguins mergulham no fundo das águas sem equipamento de mergulho. Na cerejeira milhes de flores se transformam em frutos, para pássaros, humanos, e outros animais, para que o caroço possa no solo germinar e crescer. Seus materiais se decompõem e alimentam micro-organismos, insetos. Alimenta tudo o que tem ao redor.

A natureza produz dentes, conchas, pinças, cascas de ovo, brocas de vespa, tubos e válvulas do corpo humano tudo reciclável e biode-gradável e utilizam luz do sol, o mínimo de matéria-prima, compostos simples e energia a uma temperatura de no máximo $38^{\circ} \mathrm{C}$.

Ao contrário, para fabricar uma simples torneira o ser humano precisa fundir aço a uma temperatura de $1.000^{\circ} \mathrm{C}$, e liberar gases tóxicos. Quantos aspectos técnicos podem ser usados de sistemas vivos como modelo, com a colaboração de biólogos? A natureza é a maior instituição de patentes do mundo. Cabe que nos cursos de design sejam inseridos conhecimentos em disciplinas como a biologia para poder criar produtos inovadores e principalmente "amigáveis ao meio ambiente".

A Biomimética é uma visão interdisciplinar para ver a natureza e modificar a forma atual de produção. Para esta ciência o ser humano removeu a vestimenta natural da terra e impus um padrão de concepção. A natureza cria uma série de "produtos" perfeitos, o que faz suas criações muito discretas, independentes da moda e principalmente inteligentes.

Bluchel (2009) menciona que o modelo da natureza não significa, necessariamente, que ela saiba fazer algo que os engenheiros não saibam. Mas, via de regra, a natureza sabe fazer melhor.

Os termos Biônica e Biomimética vêm sendo entendidos como sinônimos, mas são ciências complementares em quanto a biônica relaciona a biologia e a técnica a biomimética relaciona mais disciplinas de forma a ter uma visão mais ampla das potencialidades da natureza e sua aplicação no desenvolvimento de produtos ou sistemas.

Um exemplo de biônica é o desenvolvimento do protótipo do veículo da Daimler Chysler que se inspirou numa espécie de peixe ágil e de linhas fluidas (box fish), que vive nas profundezas submarinas, para projetar o Mercedes-Benz Bionic. O projeto envolveu uma equipe de engenheiros, designers, cientistas e biólogos. (Figura 15) 
Figura 15: Veículo da Daimler Chysler Box fish.

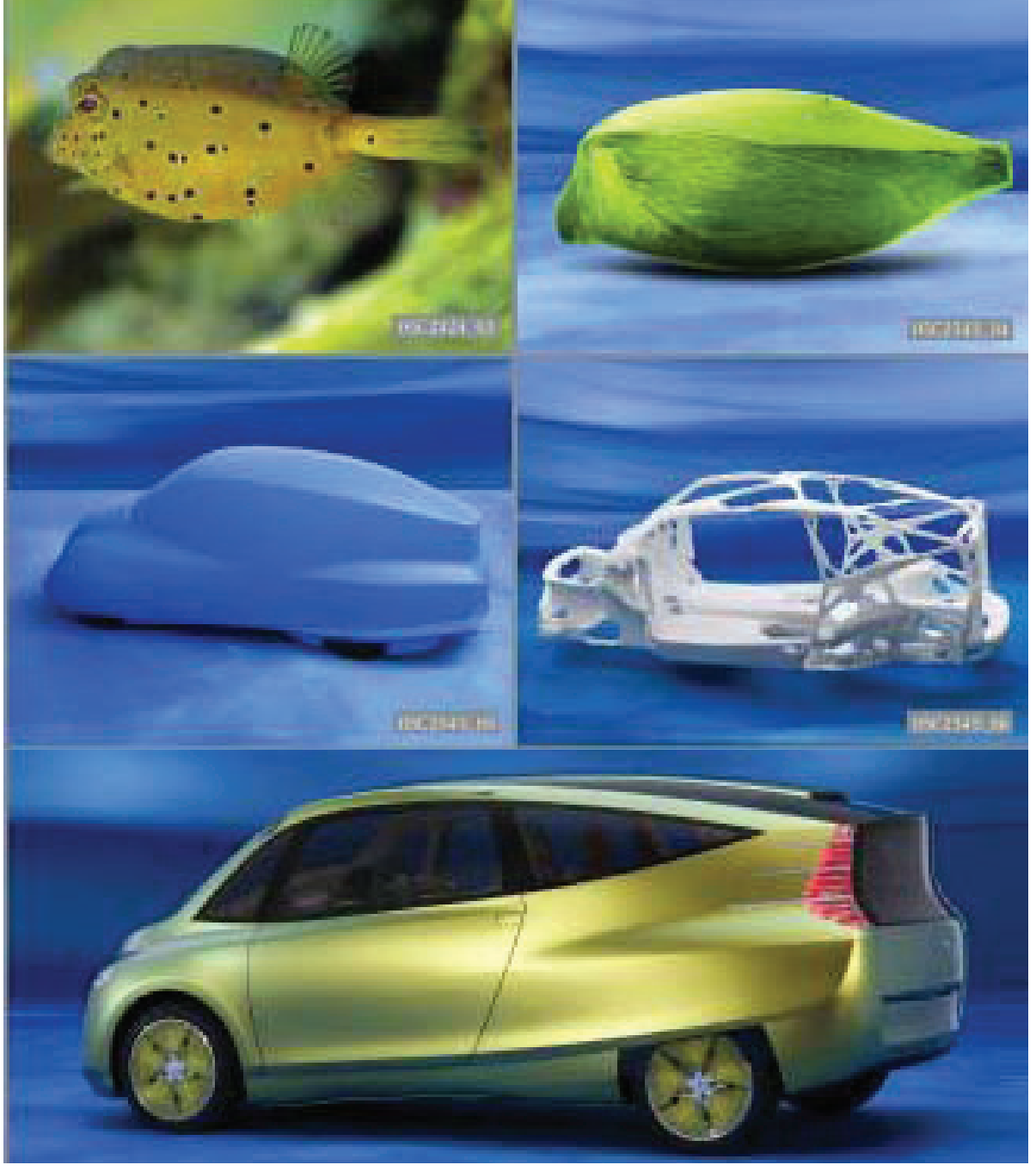

Basicamente o desenvolvimento do veículo foi uma analogia superficial de formas. Já a biomimética não se resume a uma analogia de formas, mas a uma aplicação mais consciente do potencial da natureza visando o bem-estar do ser humano e o meio ambiente. Um exemplo é a bandagem quitosana que usa um componente da casca do camarão cujas moléculas tem uma carga positiva, podendo interagir com as células vermelhas do sangue, de carga negativa, formando um coágulo. Segundo (CHALLONER, 2010) a quitosana permite que o ferimento coagule depressa, facilitando o transporte de pacientes.

Outra integração interessante da biologia com diversas áreas é a Biomimética, que significa imitação da vida. Para Benyus (1997), é uma nova ciência que estuda os modelos da natureza e depois se inspira neles ou os imita, com o objetivo de resolver problemas humanos. A Biomimética usa um padrão ecológico para ajuizar a correção das inovações, determinando o que funciona, o que é adequado e o que dura. 
Apresenta-se como um termo mais amplo que permitirá olhar de forma diferente à natureza. Justamente por esta disciplina ter surgido na fronteira de disciplinas como agricultura, ecologia, medicina, engenharia dos materiais, informática. É o resultado de uma ação interdisciplinar que pode contribuir para a criação de uma nova disciplina com a linguagem e necessidade do design.

Ewel (1991, apud Benyus, 1997) recomenda, "imite a estrutura vegetal de um ecossistema e você obterá a funcionalidade que procura". McDonough e Braungart (2010) exemplificam como essa imitação pode ser eficiente no design. Para os autores todos os materiais das formigas, inclusive as mais letais armas químicas, são biodegradáveis e uma vez devolvidos a terra se convertem em nutrientes.

Além da biologia e ecologia, uma disciplina que também deveria ser integrada ao design é a química. As informações que os designers têm sobre materiais estão voltadas na sua maioria a aspectos estéticos, de preço e resistência, os aspectos ambientais são minimizados ou superficiais. 0 designer não possui informação suficiente sobre padrões de toxicidade, resultados de testes de materiais e resultados de análise do ciclo de vida.

Goleman (2009) lembra que as toxinas flutuam na poeira do ar, na água e no solo, ou desprendem-se de uma longa lista de objetos que vão de tintas a carpetes, passando por computadores, celulares e móveis.

Por outro lado, a ideia de sustentabilidade não se limita aos materiais, pelo contrário, começa com eles. 0 material reciclado exige uma tarefa de recuperação e outra de transformação que implica em consumo de energia e geração de resíduos. Uma lata de alumínio está composta de uma combinação de alumínio e manganês e uma porcentagem de magnésio. Em um processo de reciclagem os materiais são fundidos juntos produzindo um metal mais débil e, portanto, menos útil. Apenas o "reciclado" da biosfera pode devolver o material consumido a seu estado inicial de recurso natural.

McDonough e Braungart (2010) destacam que uma roupa de poliéster e uma garrafa de água são dois exemplos de produtos que oferecem ao consumidor mais aditivos que não solicitou e que podem resultar nocivos à saúde. Os autores continuam mencionando que ao longo de pesquisas descobriram que vários produtos tais como: um mouse de computador, um barbeador, um secador de cabelo, jogo de videogame e reprodutor de CD durante o uso emitiam compostos teratógenos e/ou cancerígenos.

Os autores mencionam que outra substancia perigosa nos plásticos são os ftalatos que podem penetrar no organismo por contato como é o caso de flutuadores nas piscinas em contato com a pele fina das crianças.

Com o dito ao longo do texto, percebe-se a necessidade de uma integração maior de disciplinas com saberes específicos de impacto à saúde e ao meio ambiente, assim como, de disciplinas onde apreender novas formas de configuração de objetos. Precisamos que alunos de áreas projetuais organizem melhor seus conhecimentos para que as decisões tomadas no desenvolvimento de um produto ou serviço sejam resultado de informações reais, éticas, 


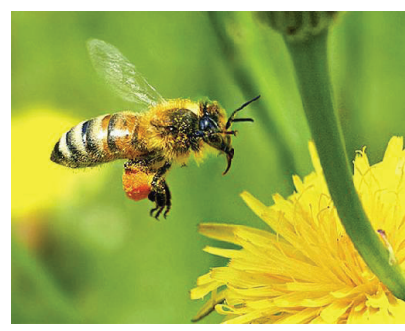

Figura 16: Abelha.

Pela aerodinâmica a abelha não deveria conseguir voar. Mas como ela não sabe disso, voa do mesmo jeito. Mary Kay Ash Os cientistas sempre tiveram dificuldade para entender o voo dos insetos porque, segundo cálculos simplificados, os bichos não deveriam ser capazes de se manter no ar por causa das asas muito pequenas. Os cálculos, no entanto, estavam errados por enxergar as asas dos insetos como plataformas estáticas, como as dos aviões. Na verdade, 0 movimento delas consegue criar pequenos vórtices no ar, 0 que permite o voo. transparentes, conscientes e interdisciplinares, talvez assim possamos trilhar o caminho da sustentabilidade.

\section{CONCLUSÃO}

A natureza é uma fonte inesgotável de exemplos de soluções eficientes que podem servir de modelos na resolução de problemas humanos. Ela pode contribuir na concepção de produtos inovadores e sustentáveis. Para isto, designers necessitam de apoio interdisciplinar da biologia técnica, biônica, biomimética, para poder entender e aplicar os conhecimentos dos sistemas naturais. (Figura 16)

Este artigo teve como objetivo apresentar os conceitos de biônica e biomimética e perceber que temos na natureza uma transformação de energia e matéria de dimensões gigantescas, um sistema tecnológico que trabalha com um fator de rendimento eficiente e que se mantem por quatro bilhões de anos.

É importante que frente aos mais diversos problemas ambientais os futuros profissionais que desenvolvem produtos utilizem a biônica e biomimética de forma consciente em seus trabalhos. Evitar que uma simples analogia formal de um sistema natural seja denominada de aplicação biônica. Espera-se que este trabalho sirva de incentivo para que professores insiram conhecimentos de biônica e biomimética nas suas disciplinas.

\section{REFERÊNCIAS}

BENYUS, Janine M. Biomimética - inovação inspirada na natureza. São Paulo: Cultrix, 1997

BLUCHEL, Kurt G. Biônica: como podemos usar a engenharia a nosso favor. São Paulo: Pub. House Lobmaier, 2009

$B O M F I M, G$. A. Fundamentos de uma teoria transdisciplinar do design: morfologia dos objetos de uso e sistemas de comunicação. In: Estudos em design, v. V, n. 2, Rio de Janeiro, 1997

COINEAU, Yves; KRESLING, Biruta. Le invenzione della natura e la biônica. Itália: Edizioni Paoline, 1986

COUTO, Rita Maria de Souza. Movimento interdisciplinar de designers brasileiros em busca de educação avançada. Tese de doutorado. PUC-Rio, 1997.

CHALLONER, Jack. 1001 Invenções que mudaram o mundo. Rio de Janeiro: Sextante, 2010.

DEMO, Pedro. Conhecimento moderno: sobre ética e intervenção do conhecimento. Petrópolis: Vozes, 1997

FAZENDA, Ivani. Interdisciplinaridade um projeto em parceria. São Paulo: Loyola, 1991.

GOLEMAN, Daniel. Inteligência ecológica: o impacto do que consumimos e as mudanças que podem melhorar o planeta. Rio de Janeiro, Elsevier, 2009

GOMES, Luiz Antonio Vidal de Negreiros. (Org.) Biônica e atividade projetual. Programa de Engenharia de Produção Área de engenharia de Produto. Rio de Janeiro: COPPE/UFRJ, 1985

GUATTARI, Félix. As três ecologias. Campinas. Papirus, 1990.

JAPIASSU, Hilton. $\mathbf{O}$ sonho transdisciplinar: e as razões da filosofia. Rio de Janeiro: Imago, 2006.

LEONARD, Annie. A história das coisas: da natureza ao lixo, o que acontece com tudo que consumimos. Rio de Janeiro: Zahar, 2011.

McDONOUGH, William; BRAUNGART, Michael. Cradle to Cradle (De la cuna a la cuna) rediseñando la forma em que hacemos las cosas. Mc GrawHill. Madrid, 2005.

RAMOS, Jaime. A biônica aplicada ao projeto de produtos. Dissertação, (Mestrado em Engenharia)

Engenharia de Produção, Universidade Federal de Santa Catarina. Florianópolis, 1993

PAZMINO, Ana. Metodosdedesign.com.br.2017

TRONCA, Dinorah Sanvitto. Transdisciplinaridade em Edgar Morin. Caxias do Sul. RS, 2006. 